\title{
ESTRUTURAS NARRATIVAS DE BOOKTRAILERS DE LITERATURA FANTÁSTICA: UMA CLASSIFICAÇÃO'
}

\section{Narrative structures of book trailers of fantastic literature: a classification}

\section{Estructuras narrativas de booktrailers de literatura fantástica: una clasificación}

\author{
Cláudio Bezerra \\ Universidade Católica de Pernambuco, Recife, Brasil \\ Pós-Doutoramento em Indústrias Criativas pela Universidade do Porto, em Portugal. Doutor em \\ Multimeios pela Universidade Estadual de Campinas (Unicamp). É professor do Mestrado Profissional \\ em Indústrias Criativas e coordenador da Especialização em Estudos Cinematográficos da Unicap \\ E-mail: claudio.bezerra@unicap.br
}

\section{Tifanny Valente Brasileiro}

Faculdade de Olinda, Olinda, Brasil

Mestra em Indústrias Criativas pela Universidade Católica de Pernambuco (Unicap). Especialista em Comunicação e Marketing de Mídias Digitais (Estácio de Sá). É professora de Publicidade e Fotografia da Faculdade de Olinda (Focca)

E-mail: tifanny.valente@hotmail.com

\section{Breno Carvalho}

Universidade Católica de Pernambuco, Recife, Brasi Doutor em Design pela Universidade Federal de Pernambuco (UFPE). É professor do Mestrado Profissional em Indústrias Criativas e coordenador da Agência de Soluções Interativas Combogó da Unicap. E-mail: breno.carvalho@unicap.br

RESUMO Este artigo propõe uma tipologia de estruturas narrativas de booktrailers de literatura fantástica a partir de um mapeamento desses produtos nos canais do YouTube das maiores editoras internacionais do subgênero fantasia. O artigo também discute as estratégias estético-narrativas e publicitárias usadas nos booktrailers para seduzir os fãs ou potenciais leitores de uma obra fantástica. Em termos metodológicos, trata-se de uma pesquisa exploratória cujo trabalho analítico envolveu uma interface entre literatura, cinema e publicidade.

PALAVRAS-CHAVE Booktrailer, Literatura fantástica, Narrativa, Audiovisual, Publicidade digital.

ABSTRACT This article proposes a typology of narrative structures of book trailers of fantastic literature. The classification was created by mapping these products in

1. Em sua primeira versão, o presente artigo foi inserido como apêndice no Relatório Técnico de Produto defendido pela coautora Tifanny Valente Brasileiro, no Mestrado Profissional em Indústrias Criativas da Universidade Católica de Pernambuco (Unicap), em 5 de agosto de 2019. O referido Relatório consta na Biblioteca Digital de Teses e Dissertações da Unicap. 
YouTube channels of the biggest international publishers of the fantasy subgenre. The paper also discusses the aesthetic-narrative and advertising strategies used in book trailers to entice fans or potential readers of fantasy. In methodological terms, this is an exploratory research in which analysis involved an interface between literature, cinema and advertising.

KEYWORDS Book trailer, Fantastic literature, Narrative, Audiovisual, Digital advertising.

RESUMEN Este artículo propone una tipología de estructuras narrativas de booktrailers de literatura fantástica. La clasificación aquí presentada, fue creada a través del mapeo de estos productos en los canales de YouTube de los editores internacionales más importantes del subgénero de fantasía. El artículo también analiza las estrategias estéticas, narrativas y publicitarias utilizadas en los booktrailers para atraer los fans o potenciales lectores de fantasía. En términos metodológicos, esta es una investigación exploratoria en la que el trabajo analítico involucra una interfaz entre la literatura, el cine y la publicidad.

PALABRAS CLAVE Booktrailer, Literatura fantástica, Narrativa, Audiovisual, Publicidad digital

\section{INTRODUÇÃO}

O booktrailer é uma peça audiovisual de propaganda criada e veiculada com o objetivo de divulgar um determinado livro nas plataformas digitais. Sua origem remonta ao trailer cinematográfico. Desde sua configuração como indústria, na primeira década do século XX, o cinema faz uso desse recurso. No início eram slides exibidos exclusivamente nas salas entre um filme e outro, com informações referentes aos próximos lançamentos. Não demorou muito para que esses anúncios fossem usados como uma estratégia publicitária sofisticada para seduzir o público. Hoje, os trailers circulam não só nas salas de cinema, mas também na televisão, na internet, em sites, blogs e em praticamente todas as redes sociais digitais, tornando-se uma importante ferramenta de movie marketing e de marketing viral (BARICHELLO e OLIVEIRA, 2010; MELISSA, 2007).

De acordo com Melissa (2007), não há uma estética padronizada no trailer cinematográfico porque o projeto estético depende do gênero do filme e do objetivo a ser alcançado; mas, como peça publicitária, o trailer é um discurso articulado que possui objetivos específicos e uma estrutura narrativa adequada para cumprir com sua função comunicativa. Nesse sentido, alguns elementos são constantes, como apresentação do enredo, locução, música, presença de personagens/atores e da data de estreia do filme. Também são frequentes, quando não há locução, o uso de diálogos e letreiros com palavras e frases na tela que apresentam o assunto do filme, direcionando o entendimento que o espectador deve ter das imagens.

Melissa (2007) considera a montagem como a base de sustentação do trailer pois reúne sequências e cenas do filme consideradas relevantes para rearticulá-las em função da mensagem publicitária que se pretende passar para o público. Nesse sentido, a autora ressalta o papel da música no trailer, de dar ritmo às imagens e criar uma ambiência sonora de impacto e envolvimento com o filme e sua história. Sem a pretensão de dar conta de toda a vasta produção de trailers cinematográficos, Melissa identifica uma estrutura narrativa comum e recorrente, composta por quatro partes, em grande número de trailers produzidos pela indústria de Hollywood. 
A primeira parte é de "introdução", em que as imagens ambientam a história. Quando há algum astro no filme, em geral as cenas iniciais do trailer mostram a sua presença. Melissa (2007) chama a segunda parte de "narração", momento de apresentação da história do filme, seus personagens, o tempo, o espaço e os principais conflitos de maneira rápida e superficial para despertar o interesse do espectador. Nessa etapa, muitas vezes é apresentado apenas o conceito do filme, estimulando a curiosidade do público. A terceira parte, "Provas", apresenta fatos e argumentos para respaldar o que já foi mostrado; são propriamente elementos de comprovação de que vale a pena assistir ao filme, como a presença dos atores protagonistas, nomes do diretor e produtores ou prêmios recebidos.

Segundo Melissa (2007), a última parte do trailer cinematográfico, "Peroração", é o momento final de convencimento e está subdividida em outras quatro partes: 1) cenas importantes da estória ou do clímax, para despertar no espectador o desejo de querer ver o filme depois; 2) nome do filme em grandes caracteres; 3 ) destaque da data de estreia; 4) créditos com informações sobre o filme: título, diretor, principais atores, trilha sonora, site, distribuidora, entre outras.

Como peça audiovisual e publicitária, o booktrailer traz muitas dessas características do trailer cinematográfico, mas é um produto diferente. Estruturado a partir de uma obra literária, portanto, sem imagens, o booktrailer deve seduzir e estimular a curiosidade com bastante cuidado para não conduzir a uma interpretação única da estória e seus personagens, destruindo assim a imaginação criativa e pessoal de cada leitor ao ler um livro. No entanto, assim como no trailer de cinema, há diferentes formas de se fazer booktrailer, com atores em cena, desenhos, animação, ilustrações, música, locução, letreiros, trechos do livro, frases de efeito, entre outras modalidades de apresentação da obra literária. Aqui também a montagem exerce um papel fundamental para estimular a aquisição e leitura de um determinado livro.

Este artigo tem como objetivo propor uma classificação geral das estruturas narrativas de booktrailers de literatura fantástica, a partir da observação e análise da produção das cinco maiores editoras internacionais do gênero: a Bloomsbury Publishing, a Penguin Random House, a Simon \& Schuster Books, Disney Hyperion, HarperCollins, e a Penguin Random House. A opção por mapear e analisar especificamente os booktrailers de literatura fantástica de fantasia se deu por ser um dos gêneros que mais tem gerado publicações que se tornam best-sellers, com desdobramentos e adaptações para outras linguagens, como filmes, quadrinhos, séries de TV e jogos.

Segundo Carmo (2015), a palavra "fantástico" vem do latim "phantasticus", que tem origem do grego "phantastikós” e significa: tudo o que é fantástico, fantasia. O que se pode dizer é que a literatura fantástica está voltada a uma narrativa imaginária, de fuga do mundo da realidade. De acordo com Todorov (2004), a literatura fantástica possui três subgêneros: terror, ficção científica e fantasia. No terror, destaca-se como característica principal a provocação do medo no leitor, apostando em personagens como fantasmas e monstros. Obras como "O Exorcista", de William Peter Blatty, e "Drácula”, de Bram Stoker, são alguns exemplos.

Na ficção científica, observa Todorov (2004), a narrativa volta-se para um contexto futurístico, com tecnologias bastantes avançadas na época em que se passa a estória. Como o nome já aponta, as estórias costumam ter um teor científico, adotando como personagens criaturas extraterrestres, robôs com inteligências artificiais, além de investir em 
viagem no tempo e universos paralelos. Como exemplos literários temos Admirável Mundo Novo, de Aldous Huxley, e Frankenstein, de Mary Shelley.

Finalmente, o subgênero fantasia, objeto deste artigo, tem como forte referência a presença da magia, com personagens místicos e sobrenaturais como fadas e elfos mágicos. Pode-se destacar como exemplos de livros desse subgênero As Crônicas de Nárnia, de C.S. Lewis, Harry Potter, de J. K. Rowling, O Senhor dos Anéis, de J. R. R. Tolkien e A Guerra dos Tronos, de George R. R. Martin.

Para dar conta do seu objetivo de propor uma tipologia de booktrailers de fantasia, este artigo é composto por quatro partes. A primeira é esta introdução, que contextualiza as origens do booktrailer e justifica a opção de análise e classificação dos trailers de livros do gênero fantástico, subgênero fantasia. A segunda parte discute em linhas gerais o que é narrativa para evidenciar os elementos específicos da narrativa audiovisual do booktrailer, construído a partir de uma interface entre literatura, cinema e publicidade. Em seguida, a partir dos elementos estético-narrativos dominantes nos booktrailers analisados, é proposto três tipos de booktrailers de fantasia: básico, híbrido e múltiplo ou complexo. Por fim, são feitos alguns comentários gerais sobre a contribuição que a tipologia pode trazer tanto para o estudo como o fazer booktrailers.

\section{ELEMENTOS ESTÉTICO-NARRATIVOS DE ANÁLISE}

Como peça de comunicação publicitária que visa a promoção e venda de livros, o booktrailer se constitui a partir de uma interface entre literatura, cinema e publicidade. Ainda que cada uma dessas linguagens tenha suas especificidades, o ponto em comum onde elas se cruzam é a narrativa, ou seja, as três contam estórias de uma determinada forma, embora com propósitos e modos distintos.

As narrativas são representações, construções discursivas sobre a realidade humana. São representações mentais linguisticamente organizadas a partir de nossas experiências de vida. Sejam elas fictícias ou fáticas, são sempre construções de sentido sobre o mundo real ou imaginado. (MOTTA, 2013, p. 83)

Embora as formas de contar estórias se transformem ao longo do tempo, não há como negar a força que a estruturação narrativa aristotélica ainda exerce quando se pretende despertar e prender a atenção do público. Para Aristóteles (1991), o efeito dramático² de uma narrativa depende fundamentalmente que esteja estruturada para o desenlace de um nó de acontecimentos. Na visão aristotélica, uma estrutura narrativa se constitui a partir da apresentação de uma situação/problema que possa suscitar perguntas sobre o andamento da estória. Trata-se, portanto, de uma estrutura interrogativa que posiciona o público na expectativa do que vai acontecer.

Vivemos e respiramos estórias, expressadas por narrativas, e quando elas são bem contadas nos prendem a atenção e são capazes de nos transmitir diversos tipos de emoções e sentimentos, como bem observou Aristóteles (1991). Diante de tantas estórias que nos cercam na sociedade contemporânea, das redes sociais e tantas outras redes de informação

2. Cabe ressaltar que Aristóteles, em sua Poética, se refere ao efeito trágico de uma tragédia. 
e comunicação (CASTELLS, 1999), a publicidade tem como desafio criar narrativas diferenciadas que prendam a atenção do público e o provoque a tal ponto de levá-lo a adquirir determinado produto.

Para um booktrailer atingir seus objetivos é fundamental encontrar uma forma narrativa adequada. Se por um lado é preciso ter cuidado para não tolher a imaginação do leitor do livro, por outro, além da persuasão, é importante investir em estratégias emocionais para fazê-lo se interessar em ler a obra literária. Como observa Xavier (2017), para lidar com estórias é preciso unir as técnicas publicitárias com as técnicas da arte, de modo semelhante ao trailer cinematográfico.

Por se tratar de um vídeo publicitário, o trailer, como defende Covaleski (2015), reúne as cinco matérias de expressão usadas no cinema: sons, imagens, impressões, sensações e significações. Esses elementos são compostos na montagem com o intuito de criar uma forma narrativa ao mesmo tempo emocionante e sedutora. Quais seriam então os elementos estético-narrativos adequados para compor um booktrailer, considerando sua natureza audiovisual e a particularidade de ser elaborado a partir de um livro?

Carvalho (2017) enfatiza que, enquanto formato de micronarrativa, os booktrailers são uma espécie de degustação rápida da obra literária, "convidando o leitor a vivenciar a trama de forma vívida e atraente por alguns segundos”(p. 38), no entanto, o apelo ao consumo não é explícito e imperativo como em um anúncio clássico, e sim sutil, insinuado. É com pequenos trechos do texto original do livro que as editoras procuram chamar a atenção dos leitores nos booktrailers.

Assim como os trailers de filmes utilizam fragmentos das obras, montando pequenas estórias, dando pistas de personagens e oferecendo elementos de aventura, emoção, medo, desconforto e suspense. Esses booktrailers podem ter ou não texto verbal; os criadores podem utilizar imagens para ilustrar determinadas passagens das estórias, com desenhos ou pessoas e lugares que remetam ao enredo.

(CARVALHO, 2017, p. 38)

Para provocar sedução e emoção, são usados no booktrailer diferentes recursos da narrativa cinematográfica, a exemplo de enquadramentos, planos e pontos de vista. Como observam Jullier e Marie (2009), a câmera pode servir para representar o ponto de vista do personagem, fazendo com que o espectador passe a "olhar com” o personagem ou "olhar no lugar" dele, além do “campo/contracampo”, que é quando a câmera mostra o ponto de vista de mais de um personagem, alternadamente.

Nas formas mais habituais do cinema narrativo, as duas acepções estão intimamente ligadas: quer a câmera coloque o espectador como testemunha, proporcionando-lhe o ponto de vista imparcial, invisível e privilegiado da testemunha em cena; quer adote o ponto de vista de um personagem, mais ou menos subjetivamente. (JULLIER e MARIE, 2009, p. 23)

A respeito dos tipos de planos, há basicamente três posições que podem ser utilizadas para situar o personagem no ambiente: o plano médio (com o qual podemos ter uma visão parcial do ambiente em que o personagem está situado, a câmera fica situada em uma distância média do personagem, fazendo com que ele ocupe uma boa parte do ambiente), o close-up (plano fechado que mostra alguma particularidade, dá foco e aproximação em algo específico, seja o rosto do personagem, 
as expressões faciais, o olhar ou algum detalhe do lugar, como um jarro, uma placa etc.), e o plano geral (com um ângulo visual bastante aberto, onde podemos ter o personagem aparecendo por inteiro no vídeo, além de uma visão maior do ambiente, proporcionando uma noção melhor da relação entre ambos).

Seja qual for o plano escolhido, há dois tipos principais de enquadramento que podem ser adotados: centralizado (no qual o objeto principal, seja o personagem ou algo que se queira em destaque, está centralizado no vídeo, é o centro principal da cena) e descentralizado (em que se pode pensar na regra dos terços, onde o objeto principal está enquadrado em um dos eixos formados por linhas imaginárias verticais e horizontais). A câmera também pode ser posta para o alto, chamada de plongée (em que temos uma visão de cima para baixo), ou para baixo, em contra-plongée (em que passamos a ter uma visão de baixo para cima). Há ainda a técnica de frontalidade, na qual o personagem olha para a câmera, como se estivesse olhando para quem está assistindo. Por último, também é possível utilizar o "desenquadramento", utilizando a câmera inclinada, ou até com algum movimento de tremor, para melhor representar, por exemplo, um ponto de vista de um personagem com embriaguez, mal-estar, entre outros.

Outro aspecto de grande importância na construção de um booktrailer é o som. Ele pode enfatizar o que se está sendo visto, narrar parte da estória (ou só apresentar a sinopse), vir em forma de diálogos, locuções em off, citações ou ruídos (como sons da água escorrendo, alguém andando, do vento etc.). O som também pode ser inserido como uma música de fundo ou, como diz Langie, (2005), uma música que procura acompanhar explicitamente a emoção de alguma cena.

A duração do booktrailer pode também influenciar no resultado final, sendo até determinante na hora da decisão do consumo de um terminado trailer de livro. Dependendo da proposta narrativa, um trailer muito longo pode se tornar cansativo e desestimulante, fazendo com que a pessoa que estiver vendo perca o interesse em assisti-lo até o final, enquanto um booktrailer muito curto pode não ter uma a duração suficiente para causar algum tipo de interesse no público-alvo do livro.

Do mesmo modo que o trailer cinematográfico, a montagem também é crucial no booktrailer. O tipo de corte das cenas, os efeitos utilizados, as transições, a relação entre imagem e som, em suma, a forma como a narrativa é construída para despertar o interesse e emocionar 0 espectador-leitor.

\section{TIPOLOGIA DE BOOKTRAILERS DE FANTASIA}

Para propor uma tipologia de narrativas de booktrailers de literatura fantástica do subgênero fantasia, optamos por usar como parâmetro a produção das cinco maiores editoras internacionais selecionadas, analisando os trailers de livros existentes nos canais do YouTube de cada uma delas. Cabe ressaltar que a internet e as redes sociais são os ambientes por onde mais circulam os booktrailers (CARVALHO, 2017). Até a finalização deste trabalho foram mapeados um total de 180 títulos, distribuídos da seguinte forma: 67 na Bloomsbury Publishing, 46 na Penguin Random House, 42 na Simon \& Schuster Books, 11 na Disney Hyperion, 09 HarperCollins e apenas 05 na Penguin Random House.

Ainda que a produção brasileira seja incipiente, procuramos também observá-la no intuito de identificar se havia alguns elementos específicos nos booktrailers nacionais de literatura fantástica. Foi usado também 
como critério de seleção as postagens nos canais do YouTube das cinco maiores editoras deste gênero no Brasil. Foram encontrados, visualizados e analisados 39 trailers de livro na Editora Intrínseca, 17 na da Rocco, 11 na Galera Record, 03 na LeYa e 02 da HapperCollins Brasil. Foi possível constatar que a maioria dos booktrailers das editoras nacionais é de produção internacional, com apenas algumas adaptações feitas para serem divulgadas ao público-leitor brasileiro, como dublagem e/ou a inclusão de legendas em português. Por esse motivo não os consideramos para este artigo.

Os 180 títulos mapeados foram visionados várias vezes para identificar a estrutura narrativa, os elementos sonoros e visuais e as técnicas usadas em cada um para despertar o interesse do público consumidor. A partir da identificação de características comuns em determinados booktrailers do corpus analisado, foi possível agrupá-los em três grandes tipos, os quais nomeamos como básico, híbrido e múltiplo ou complexo.

Cabe ressaltar que os termos adotados para essa tipologia de booktrailers pretendem expressar o que caracteriza cada uma das três grandes formas narrativas identificadas, mas não estão atrelados a hierarquias de qualidade e/ou eficácia enquanto estratégia publicitária. O objetivo da categorização é tão somente apontar as características gerais dos elementos estéticos-narrativos dominantes nos booktrailers visionados.

\section{Básico}

Os booktrailers do tipo básico são os que, normalmente, possuem uma narrativa linear, com voz indireta (narrador fala do personagem e da estória), ou por meio de letters (textos na tela), com apresentação breve da sinopse, efeitos básicos de animação em 2D, utilizando muitas vezes a imagem da capa (mas pode ter outras imagens para ilustrar, também sob efeitos básicos, como fusões), trechos do texto do livro, palavras-chaves de efeito, frase de impacto, uma trilha sonora de fundo (em geral, a música é instrumental) e finaliza com a capa do livro (contendo, em sua maioria informações como data de lançamento ou endereço de redes sociais). Em média, possuem de 30 segundos a pouco mais de um minuto de duração.

Como exemplo de booktrailer básico, podemos citar "Throne of Glass" do livro homônimo da autora Sarah J. Maas, postado no dia 26 de julho de 2012 no canal do YouTube da Editora Bloomsbury Publishing, com um minuto e dez segundos de duração. O livro traz a história de Celaena, uma jovem de 18 anos que está cumprindo uma sentença nas minas de sal sujas e sombrias de Endorvier, por ser uma assassina. Celaena estava quase perdendo as esperanças de sair do local, quando recebe a proposta de participar de uma competição no lugar do príncipe de Adarlan e aceita o desafio em troca da liberdade. Em cada duelo, a vida de Celaena corre perigo.

O booktrailer de Throne of Glass é feito com imagens da ilustração da capa do livro com alguns efeitos de animação e transição, voz indireta e uma narrativa linear, acompanhada por uma música instrumental de aventura e ação , estilo ópera. Não há locução, as informações são apresentadas por letterring e booktrailer começa com o nome da editora Bloomsbury em cor azul sobre fundo branco. Em seguida, uma fusão nos mostra a silhueta do desenho de um corpo feminino envolvido por uma névoa e entra em caracteres a expressão "conheça Celaena”, com destaque para o nome da personagem em cor vermelha e letra de maior tamanho.

Na sequência, enquanto um efeito visual aproxima aos poucos da imagem de mulher, entram e saem palavras-chaves que qualificam 
a personagem: "bonita”, "mortal”, "uma assassina treinada”. Depois, aparecem frases curtas, de impacto, informando o local da história e a problemática em torno da heroína. A última frase aparece pouco antes da imagem do rosto de Celaena e, em tom de suspense, arremata: "ela está para descobrir seu verdadeiro destino”. Em fusão, sobre a imagem do rosto da protagonista, entra o título da obra, Throne of Glass, preenchendo toda a tela, em seguida, entra a capa do livro, informações sobre a página da série Throne of Glass no Facebook e o nome da editora Bloomsbury. A última imagem mostra as capas dos quatro livros anteriores da série. Até a elaboração deste artigo, esse booktrailer possuía 112.992 visualizações, 730 curtidas positivas e 11 negativas.

O booktrailer "Throne of Glass" possui uma narrativa simples comparada ao que Covaleski (2015), Jullier e Marie (2009) apresentam como possibilidades de exploração dos elementos estético-narrativos da linguagem cinematográfica, mas isso não quer dizer que seja ruim, é apenas uma forma mais curta e, provavelmente, mais barata de criar um trailer de livro.

\section{Híbrido}

Nos booktrailers híbridos, além das características do tipo básico já citadas, a narrativa tanto pode ser linear quanto não linear e a narração pode ser direta (personagem fala por si) ou indireta (narrador fala do personagem e da história). Também podem ter depoimentos dos autores, pequenos textos elogiosos de revistas especializadas, locução e/ou diálogos. A natureza híbrida desses booktrailers está mesmo relacionada a essa mistura de elementos estético-narrativos de diferentes fontes em maior nível de articulação do que os booktrailers básicos. Em geral, possuem mais de um minuto de duração.

Como exemplo do tipo híbrido temos o booktrailer de Finale, da autora Becca Fitzpatrick, que podemos ver no canal do YouTube editora Simon \& Schuster Books, postado no dia 19 de novembro de 2012. O livro Finale é o quarto volume da série literária Hush Hush e vem com a continuação da saga de Nora e Patch. Na narrativa, ambos os personagens pensavam ter se livrado dos problemas, mas, com o Mão Negra fora, Nora teve que ser a líder do exército nefilim com a missão de acabar com a raça dos anjos caídos, ou seja, teria que destruir Patch. Nora, porém, decide bolar um plano junto com Patch para manipular ambos os lados, na tentativa de convencer os nefilins de que é um erro manter essa luta contra os anjos caídos, com o objetivo de terminar com essa guerra logo no início. Os planos terminam dando errado e Nora e Patch se veem tendo que encarar suas diferenças e decidir, definitivamente, entre ignorar tudo ou destruir o amor pelo qual eles tanto lutaram até agora.

O booktrailer "Finale" apresenta cenas gravadas com atores em preto e branco, além de uma narrativa direta contendo diálogos entre dois personagens da trama, semelhante a um trailer de filme, com uma trilha sonora instrumental de fundo de uma música agitada que segue até o fim, porém, não é tão sofisticado como os trailers cinematográficos. O booktrailer termina com a exibição da capa do livro, seguindo pela aparição de todos os quatro volumes da série com a frase "a conclusão épica de Hush, Hush, de Becca Fitzpatrick's, best-seller do New Yourk Times". Até o final deste trabalho, o booktrailer "Finale" tinha 315.053 visualizações, 3.200 curtidas positivas e 77 negativas. 


\section{Múltiplo ou complexo}

Os booktrailers do tipo múltiplo ou complexo são mais elaborados, adotam a estética do trailer cinematográfico em sua plenitude (cor, luz, ambientação, customização dos personagens, recursos tecnológicos sofisticados etc.), podem ser feitos com animação em 3D ou com atores interpretando os personagens em um cenário que remete fielmente à história do livro. As cenas são gravadas ou criadas em computador especificamente para o booktrailer (com a produção e caracterização pensada em cada detalhe, como roupas, cabelo, maquiagem etc.), com investimento em planos sequências fílmicas, podendo ter diálogos, locução, ruídos, sequências com trechos do livro e/ou depoimentos do autor(a) em cena falando sobre a obra, trilha sonora mais bem trabalhada, com edição que pode mudar o tom ou até a música quando muda de cena ou uma ação, além de efeitos digitais diferenciados. A estruturação narrativa assemelha-se ao booktrailer híbrido, podendo ser linear ou não linear, e a locução também pode ser direta ou indireta. Ainda que tenham semelhanças, a forma mais elaborada e complexa de articulação dos elementos estético-narrativos e o uso recorrente das possibilidades expressivas da linguagem cinematográfica diferenciam o booktrailer múltiplo do híbrido.

Um exemplo de booktrailer múltiplo é o "The School for Good and Evil” do escritor Soman Chainani, postado em 27 de outubro de 2017 no canal do YouTube da HarperKids, selo da Editora HarperCollins. O livro best-seller The School for Good and Evil é o primeiro volume de uma trilogia que conta a história do povoado de Gavaldon, local em que, há mais de dois séculos dois adolescentes somem misteriosamente a cada quatro. As famílias costumam trancar seus filhos por temerem que sejam sequestrados. A lenda conta que os jovens que desaparecem, na verdade, são levados para The School for Good and Evil, onde passam a estudar para se tornarem heróis e vilões das histórias de conto de fadas. Então conhecemos as melhores amigas Shopie e Agatha, que torcem para serem as escolhidas desta vez. Sophie sonha em se tornar uma princesa, e Agatha, que é o oposto da sua amiga e cansada das lendas de sua cidade, só quer sair de Gavaldon. O destino termina pregando uma peça nelas, e a partir daí as duas passam a viver uma aventura que irá mostrar quem são de verdade.

O trailer "The School for Good and Evil” é feito com animações e ilustrações muito bem elaboradas em 3D, ricas em detalhes, pensadas e usadas como estratégia de sedução, aspecto que Langie (2005) aponta como crucial na publicidade. O booktrailer inicia com uma narrativa indireta de uma voz infantil apresentando o ambiente e o principal conflito da estória, acompanhada por imagens animadas de situações simbólicas do universo abordado e uma música instrumental impactante de suspense e aventura acrescida de efeitos sonoros que reforçam o clima de tensão associado ao livro.

Após a apresentação da sinopse, entra uma frase em lettering que procura dialogar diretamente com o leitor, em duas telas. A primeira, diz: "os portões serão abertos”. A segunda: "para a escola dos seus sonhos”. Em seguida, surge a animação de um livro aberto com uma citação de Gregory Maguire, autor de Wicked, clássico da literatura fantástica, com elogios ao autor do livro The School for Good and Evil. Nossa atenção é direcionada à referida citação pela mão de um ser mascarado que em seguida voa. A cena seguinte é de uma lápide com outra citação elogiosa, dessa vez de Maria Tatar, autora de Os Contos de Fadas Clássicos. 
Há ainda uma terceira citação, de Robert Lawrence Stine, autor de Goosebumps, que aparece dentro uma figura geométrica criada após o efeito visual de um dedo indicativo apontar para o céu. $O$ texto da citação de Stine é uma frase sintética e de grande apelo para os fãs do gênero: "uma corrida selvagem e perigosa através dos contos de fadas... adorei este livro”. Essas citações aparecem como uma estratégia publicitária de transferência de credibilidade para o livro divulgado pelo booktrailer.

O booktrailer "The School for Good and Evil” segue com algumas palavras-chaves como "o maior" e "mau", e a frase de efeito "o livro de 2013", que aparecem sobre animações em 3D (um machado de guerra, as costas de uma mulher tatuada de onde sai um dragão cuspindo fogo, o esqueleto de um dinossauro que sai voando de um castelo e as portas do castelo se fechando para uma mulher que pretendia sair) no ritmo acelerado da trilha sonora de aventura. Em seguida, a música termina, aparece o título do livro em letras grandes e uma fada animada olha para ele, vira-se em nossa direção, pede silêncio com um sussurro e o dedo nos lábios e voa rapidamente. A fada avança sobre a tela transformando-se na boca de um mostro que parece vir nos engolir. Na sequência, entram a data de lançamento do livro e o endereço de sua página na internet.

Em termos estético-narrativos, "The School for Good and Evil” não deve nada a um sofisticado trailer cinematográfico. Até a elaboração deste artigo, o booktrailer tinham 56.231 visualizações, 75 curtidas positivas, e apenas duas negativas. Os trailers de livro do tipo múltiplo ou complexo em geral têm mais de um minuto de duração.

\section{CONSIDERAÇÕES FINAIS}

A partir do mapeamento e análise das formas narrativas dos booktrailers publicados pelas cinco principais editoras internacionais do gênero literatura fantástica de fantasia, foi possível constatar que esse formato de divulgação de livros adota diretrizes estéticas e narrativas do trailer de cinema e de técnicas de propaganda audiovisual. O mapeamento permitiu uma classificação de três grandes categorias de booktrailers: básico, híbrido e múltiplo ou complexo. Cabe enfatizar que essa categorização se deu a partir de recorrências que apontam estruturas estético-narrativas possíveis para a construção de booktrailers, o que não quer dizer que uma categoria seja melhor que a outra, pois a classificação é descritiva, não se ateve a uma análise estética qualitativa nem tampouco procurou observar a eficácia comunicativa e publicitária dos booktrailers visionados.

O fato é que, independente do modelo estético-narrativo, o booktrailer é uma importante peça de comunicação publicitária para a promoção de livros, sobretudo, para o público jovem. Feito com planejamento e pensando no perfil do seu público-alvo, pode ser eficaz na divulgação de novos livros e dos seus autores, com um grande potencial em um ambiente de cultura colaborativa (JENKINS, 2014 e 2015), onde qualquer usuário pode interagir por meio de curtidas, comentários e também pode compartilhar o booktrailer em suas redes sociais e blogs pessoais. Nesse sentido, a partir do corpus de booktrailers analisado, a estruturação narrativa aristotélica, de nó e deselance, parece ainda atual e adequada para a comunicação publicitária.

O ideal é sempre usar as mídias digitais sempre a nosso favor, mas entrar nesse meio também tem seus desafios - conquistar e prender a atenção do público é o maior deles. Por isso, conhecer os elementos 
narrativos mais utilizados e apostar neles quando for criar um booktrailer pode ajudar no resultado final, que é atingir o target a tal ponto dele querer consumir o produto (o livro) depois de assistir ao trailer, e/ou divulgálo por livre e espontânea vontade, expandindo ainda mais o alcance de visualização do booktrailer, ajudando a promovê-lo gratuitamente.

Por fim, cabe apontar que, apesar de ser criada a partir do subgênero de fantasia, a tipologia proposta neste artigo pode ser útil e aplicada também para a análise de outros gêneros e subgêneros de booktrailers, uma vez que, em linhas gerais, as características e os elementos estéticonarrativos identificados para a proposição da tipologia são os mesmos da materialidade formal de todo booktrailer, um produto audiovisual que se constitui na interface entre literatura, cinema e publicidade.

\section{REFERÊNCIAS}

ARISTÓTELES. Poética. In: Os pensadores, Aristóteles, 4. ed. v. 2. São Paulo: Nova Cultural, 1991. BARICHELLO, E. M. M. R.; OLIVEIRA, C. C. O Marketing viral como estratégia publicitária nas novas ambiências midiáticas. Em Questão, Porto Alegre, v. 16, n. 1, p. 29-44, jan./jun. 2010.

BOOKTRAILER: Throne of Glass by Sarah J Maas. Bloomsburry Publishing. 1'10". YouTube. 2012. Disponível em: https://www.youtube.com/watch?v=j_t1kXaDtRQ. Acesso em: 05 abr. 2019.

BOOKTRAILER: Finale by Becca Fitzpatrick. Simon e Schuster Books. 1'07". YouTube. 2012. Disponivel em: https://www.youtube.com/watch?v=e-2NiblvouE\&list=PL71r30WGsTFvidXHoPFim6IApzgnhKrY\&index=30. Acesso em: 18 abr. 2019.

BOOKTRAILER: The School for Good and Evil by Soman Chainani. Harper Kids. 1'04". YouTube. 2017. Disponível em: https://www.youtube.com/watch?v=bY-1_08Qh7o. Acesso em: 10 abr. 2019.

CARMO, A. A. do. Considerações sobre o fantástico na literatura. Memento, Belo Horizonte, v. 6, n. 1, jan./jun. 2015. Disponível em: https://dialnet.unirioja.es/descarga/articulo/5106115. pdf. Acesso em: 24 mar. 2019.

CARVALHO, D. Booktrailers: Novas Formas de Consumir Livros e Micronarrativas que Capturam o Leitor. Signos do Consumo, São Paulo, v. 9, n. 1, p. 36-45, jan./jun. 2017.

CASTELLS, M. A sociedade em Rede. São Paulo: Paz e Terra, 1999.

COVALESKI, R. Cinema e Publicidade: intertextos e hibridismo. Rio de Janeiro: Confraria do Vento, 2015.

JENKINS, H.; GREEN, J.; FORD, S. Cultura da conexão: criando valor e significado por meio da mídia propagável. São Paulo: Aleph, 2014.

JENKINS, H. Invasores do texto. Rio de Janeiro: Marsupial, 2015.

JULLIER, L.; MARIE, M. Lendo as imagens do cinema. São Paulo: Senac, 2009.

LANGIE, C. O trailer e o processo de sedução no cinema. Sessões do Imaginário. Porto Alegre, v. 14, n. 10, p. 15-23, dez. 2005.

MELISSA, C. Trailer: cinema e publicidade no mesmo rolo. Goiânia: Edição do autor, 2007.

MOTTA, L. G. Análise crítica da narrativa. Brasília: Editora UNB, 2013.

TODOROV, T. Introdução à Literatura Fantástica. 3. ed. São Paulo: Perspectiva, 2004.

XAVIER, A. Storytelling: histórias que deixam Marcas. Rio de Janeiro: Best Business, 2017. 